\title{
Recycling of ashes from thermal stations for the production of an ecological mortar: New application in civil engineering
}

\author{
Redouane Mghaiouini ${ }^{1,2 *}$, Abdelhadi Mortadi ${ }^{2}$, Dennoun Saifaoui ${ }^{3}$, Mohammed Salah ${ }^{4}$, \\ Abderrazzak Graich ${ }^{2}$, El ghaouti Chahid ${ }^{2}$, Garmim Taoufik ${ }^{2}$, Abderrahmane Elmlouky ${ }^{2}$, \\ Brahim Mrani ${ }^{5}$, Hassan Ghanim ${ }^{5}$, Mohamed Monkade ${ }^{2}$ and Abdeslam El Bouari ${ }^{1}$ \\ ${ }^{1}$ Department of Chemistry, Physical Chemistry Laboratory Applied Materials, Faculty of Sciences-Ben \\ M'sik, Hassan II University, Casablanca Morocco. \\ ${ }^{2}$ Department of Physics, Condensed Matter Laboratory, Faculty of Sciences, Chouaib Doukkali \\ University, El Jadida Morocco. \\ ${ }^{3}$ FSAC - UH2C, Laboratory for Renewable Energy and Dynamic Systems, Casablanca, Morocco \\ ${ }^{4}$ Department of Chemistry, Molecular Modeling and Spectroscopy Research Team, Faculty of Sciences, \\ Chouaïb Doukkali University, El Jadida, Morocco. \\ ${ }^{5}$ Laboratory of Nuclear, Atomic, Molecular, Mechanical and Energetic, Faculty of Sciences, Chouaïb \\ Doukkali University, El Jadida, Morocco.
}

\begin{abstract}
The main idea of this work is to investigate about the flexural and compressive forces of the mortar, which was developed from fly ash, hearth ash, and magnetized water with different times of magnetization. The results of this work reveal that the flexural and compressive force of mortars realized with magnetized water is higher than those prepared with non magnetized water. The best result of increasing the flexural and the compressive forces of the mortar are obtained when the water magnetization time is equal to $20 \mathrm{~min}$. The growth in flexural and the compressive forces of the mortar elaborated with magnetized water is proportional to the magnetization time.
\end{abstract}

*Corresponding author: redouanemghaiouini@gmail.com 


\section{Introduction}

The cement manufacturing industry is responsible for around 5\% of global carbon dioxide $\left(\mathrm{CO}_{2}\right)$ emissions [1]. This alarming number has called for a deep reflexion to replace cement with other materials. Fly ash is a by-product made in thermal units. The country's dependence on coal for power generation is increasing and therefore the production of fly ash will also be greater. This widely available unused material can be used as a partial replacement for cement, as it has important cementations properties. According to the literature [2], the magnetic water ameliorate the strength of concrete by almost $50 \%$. Thus, the use of magnetized water can reduce the use of cement in concrete. The change of characteristics of water by the action of magnetic source was cited in many papers within the literature [3-11]. In fact, water under a magnetic source undergoes many modifications in its physical properties (optics, electromagnetism, thermodynamics, and mechanics properties) compared with natural water. Xiao-Feng Pang et al. [12] have investigated the influences of the magnetic flux on physical properties of water (soaking effect, electric conductivity, thermal properties, hydrophobicity of water to materials and refraction index), as reported by them [12], these changes are caused by the modifications of micro-structures of water under the action of magnetic source. Nan Su et al. [13] have studied the effect of magnetized water on mortar and concrete containing fly ash, they found that magnetized water can improve the fluidity of fresh mortar and, at its solidification, and compressive forces. Huinan Wei et al. [14] have also worked on the influence of magnetized water in construction materials, they concluded that the utilization of magnetic water can improve the cracking resistance of materials. The amount of researches published on the influence of magnetized water on mortars remains insufficient, especially for the mortar laborite with the fly ash (pozzolanic material) or hearth ash. The recapture of those ashes from thermal installations will decrease the rejection of waste in nature and can improve the mechanical characteristics of the mortars [15-17]. Thus, the aim of this paper is to encourage the recuperation of the ashes and increase the standard of the mortar with a completely unique technology based on magnetized water. Thus, this work brings a more explanation of the mechanism of action of magnetized water on the properties of mortar. The results of this paper are going to be very helpful for engineers in building and construction to raise the use of magnetic water within the development of the new generation of mortars with good quality and cheap price.

\section{Material and Preparation 2.1 Preparation of the mortar}

Mortar is a blending of sand, hydraulic binder (cement or lime), and water. Herein, we focus in the valorization of the fly ash of thermal installations to formulate the mortar, which help to reduce the pollution fair. The fly ash (FA) is added as a replacement of the cement with different proportions of FA. The mass ratio, FA/cement adopted within the present work (Table 1) is adequate to $10 \%$ with reference (NFEN196-1). The mortars were arranged as a pieces of dimensions $4 \times 4 \times 16 \mathrm{~cm}$ (figure 1). The pieces were lifted in the open air, then they were tested after 28 days (mechanical resistance to bending and compression). 


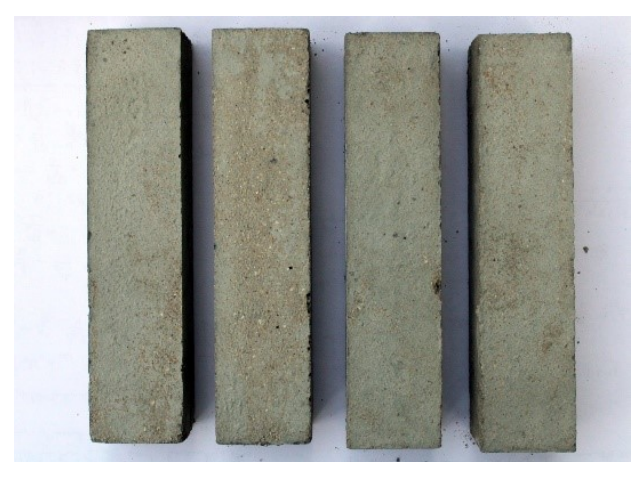

Fig. 1 Fly ash samples

Table 1 contains the different composition of the mortars. Mortar B0 is the reference. Mortar B10 was obtained by replacing part of the cement with fly ash (10\% in masse).

Table 1 Mortar formulation B0 and B10.

\begin{tabular}{ccccc}
\hline Elements & Fly ash(g) & Cement(g) & Sand(g) & water(g) \\
\hline B0 & 0 & 450 & 1350 & 225 \\
B10 & 45 & 405 & 1350 & 225 \\
\hline
\end{tabular}

\subsection{Cement}

The cement employed herein is CEM II (CPJ45: Moroccan standard NM 10.1.004). It's a hydraulic cement of $81.5 \%$ clinker, $12 \%$ limestone, the remainder is gypsum which regulates the setting. The chemical composition of CPJ 45 cement is presented in Table 2.

Table 2 Chemical composition of CPJ45 cement

\begin{tabular}{cccccccc}
\hline Cement & $\% \mathrm{SiO}_{2}$ & $\mathrm{\% Al}_{2} \mathrm{O}_{3}$ & $\mathbf{\% F e}_{2} \mathrm{O}_{3}$ & $\% \mathrm{CaO}$ & $\% \mathrm{MgO}$ & $\% \mathrm{SO}_{3}$ & $\% \mathrm{~K}_{\mathbf{2}} \mathrm{O}$ \\
\hline CPJ 45 & 17 & 5 & 3 & 63 & 2.3 & 3.33 & 1.2 \\
\hline
\end{tabular}

\subsection{Sand}

The sand utilized comes from the coast (Oualidia Morocco). Its particles analysis was comply with standard NF P18-560 [16] with an electric sieve; the results obtained are summarized within the graph in Figure 2. 


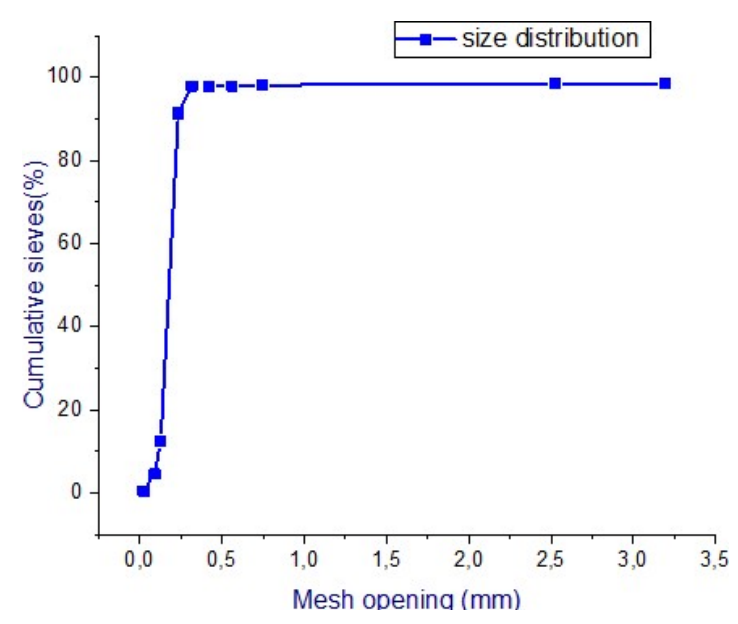

Fig. 2 Particles distribution of the sand

The grains curve indicates that the predominant grains is between $0.200 \mathrm{~mm}$ and $0.315 \mathrm{~mm}$. Thus, the sand used is uniform and conforms to the fine grains. The apparent density of the sand used decided by considering a proportion of pores $(41.5 \%)$ consistent with the reference [18]. The bulk density information's are presented in Table 3.

Table 3 Bulk density information's

\begin{tabular}{ccc}
\hline Bulk density without compaction & Bulk density with compaction & Actual density \\
\hline $\mathbf{1 , 4 3 g} / \mathrm{cm}^{3}$ & $1,54 \mathrm{~g} / \mathrm{cm}^{3}$ & $2,77 \mathrm{~g} / \mathrm{cm}^{3}$ \\
\hline
\end{tabular}

The actual density obtained, is equal to $2.77 \mathrm{~g} / \mathrm{cm}^{3}$, which comply with the specific weight of fine sand $\left(2.65 \mathrm{~g} / \mathrm{cm}^{3}\right)$.

\subsection{Fly ash and hearth ash}

\subsubsection{Fly ash}

Coal fly ash is a very fine powder obtained from the combustion of pulverized coal within the boilers of thermal power plants (Jorf Lasfar "JLEC"). The fly ash posses a gray color and have a smooth and glossy surface [19], like cement powder (Figure 3). 


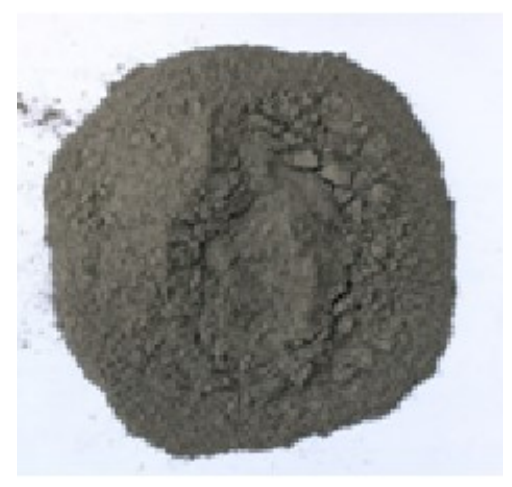

Fig. 3 The visual appearance of fly ash

Each sample was obtained by dividing several $5 \mathrm{~kg}$ samples. Cutting consists of dividing the sample into four equal parts. Two opposite parts are recovered then homogenized. One among these last two parts is cropped then on. The operation is often repeated three or four fold to get a stratified sample [20]. Table 4 summarizes the composition of the fly ash.

Table 4 The chemical elements in the fly ash in percent $\%$

\begin{tabular}{cccccccc}
\hline $\mathrm{SiO}_{2}$ & $\mathrm{Al}_{2} \mathrm{O}_{3}$ & $\mathrm{Fe}_{2} \mathrm{O}_{3}$ & $\mathrm{SiO}_{2}+\mathrm{Al}_{2} \mathrm{O}_{3}+\mathrm{Fe}_{2} \mathrm{O}_{3}$ & $\mathbf{C a O}$ & $\mathbf{M g O}$ & $\mathrm{SO}_{3}$ & $\mathbf{K}_{2} \mathrm{O}$ \\
\hline $\mathbf{5 7}$ & 34 & 3,4 & 94,4 & 5,05 & 0,02 & 0,5 & 0,03 \\
\hline
\end{tabular}

The chemical constitution of the ash indicates that the sum of the percentages of the elements: $\mathrm{SiO}_{2}, \mathrm{Al}_{2} \mathrm{O}_{3}$, and $\mathrm{Fe}_{2} \mathrm{O}_{3}$ is $94.4 \%$. Thus, we classify them among the ashes of aluminous silica. The ash composition is presented in Figure 4. Two peaks of mullite and quartz were observed during this experiment. In combustion, these minerals change their structure and provides rise to a weak crystallized part within the sort of mullite and quartz and anamorphous part [16]. This result corresponds perfectly to the mineralogical composition of the bottom ash. 


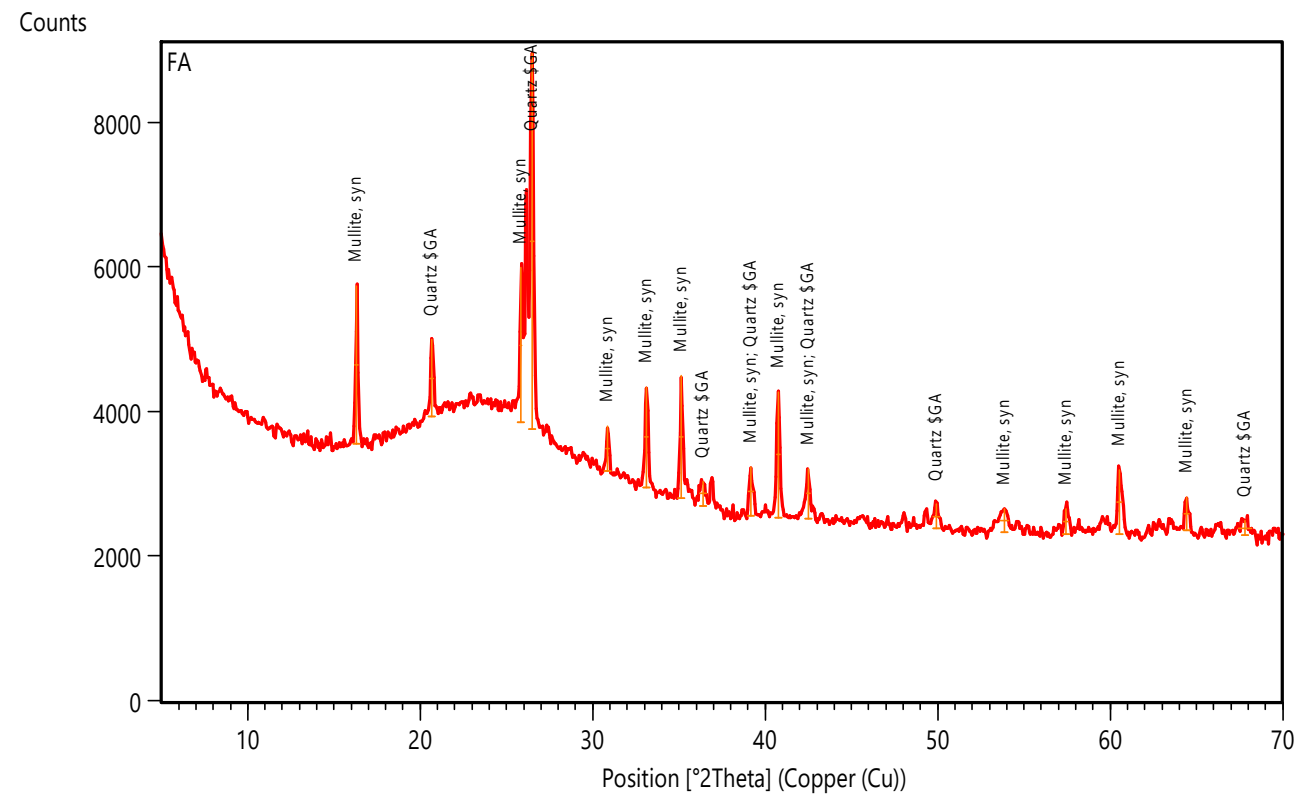

Fig.4 The mineralogical spectrum of the fly ash used 


\subsubsection{Bottom ash}

The Bottom ash (BA)/cement mass ratios is equal to $10 \%$. The process of preparation is the same as that of fly ash. The mortars prepared with Bottom ash are presented in Figure 5. Table 5 present the different formulation of mortar elaborated from bottom ash.

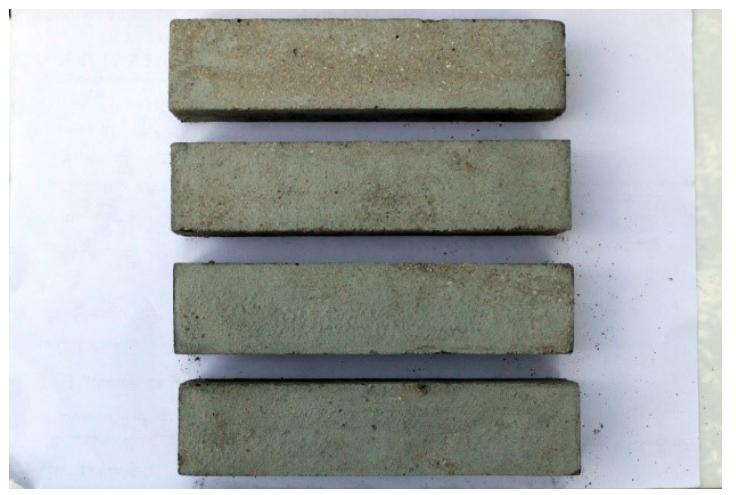

Fig. 5 Samples of bottom ash mortar

Table 5 Mortar composition (gunity)

\begin{tabular}{lcccc}
\hline Elements & Bottom ash & Cement & Sand & Water \\
\hline B0 & 0.00 & 457.07 & 1350 & $\mathbf{2 2 5}$ \\
\hline B10 & $\mathbf{5 2 . 0 7}$ & $\mathbf{4 0 5}$ & $\mathbf{1 3 5 0}$ & $\mathbf{2 2 5}$ \\
\hline
\end{tabular}

The outcomes of the analysis of the chemical composition of mortar produced from bottom ash (table 6), indicate that more than $80 \%$ of the chemical constitutions of the ashes were composed principally by $\mathrm{SiO}_{2}, \mathrm{Al}_{2} \mathrm{O}_{3}$, and $\mathrm{Fe}_{2} \mathrm{O}_{3}$.

Table 6 Composition of the bottom ash used by $\%$

\begin{tabular}{cccccccccccc}
\hline $\mathrm{CaO}^{2}$ & $\mathrm{SiO}_{2}$ & $\mathrm{Fe}_{2} \mathrm{O}_{3}$ & $\mathrm{Al}_{2} \mathrm{O}_{3}$ & $\mathrm{~K}_{2} \mathrm{O}$ & $\mathrm{Na}_{2} \mathrm{O}$ & $\mathrm{ZnO}$ & $\mathrm{PbO}$ & $\mathrm{SO}_{3}$ & $\mathrm{MgO}$ & $\mathrm{CaO}_{\text {free }}$ & $\mathrm{LOI}$ \\
\hline 1.92 & 52.07 & 8.86 & 23.34 & 1.9 & 0.4 & 0.01 & 0.01 & 1.87 & 1.09 & 0.29 & 8.24 \\
\hline
\end{tabular}

The X-ray diffraction analysis indicates the presence of two peaks, the first one is for quartz $\left(\mathrm{SiO}_{2}\right)$ and the second one corresponds to mullite (Figure 6). This result can be explicated by the mineralogy of the coal used, which generally consists of crystalline silica in the form of quartz and phyllite minerals from the clay group (shales)[18]. 


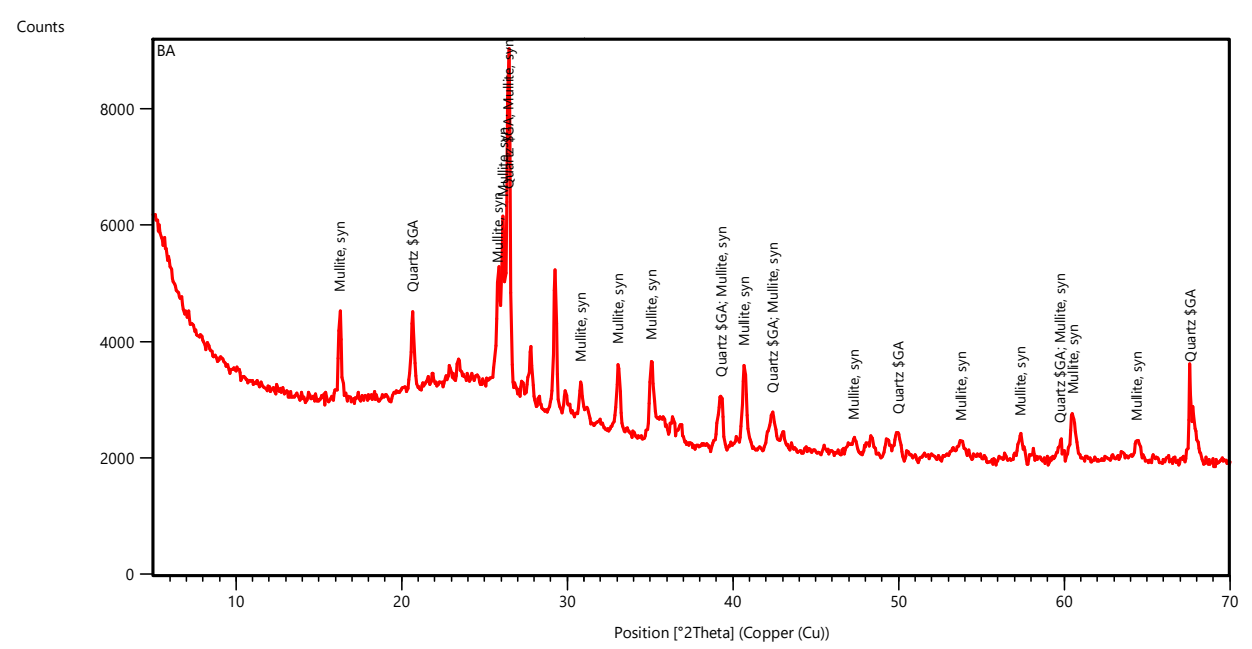

Fig.6 The mineralogical spectrum of bottom ash
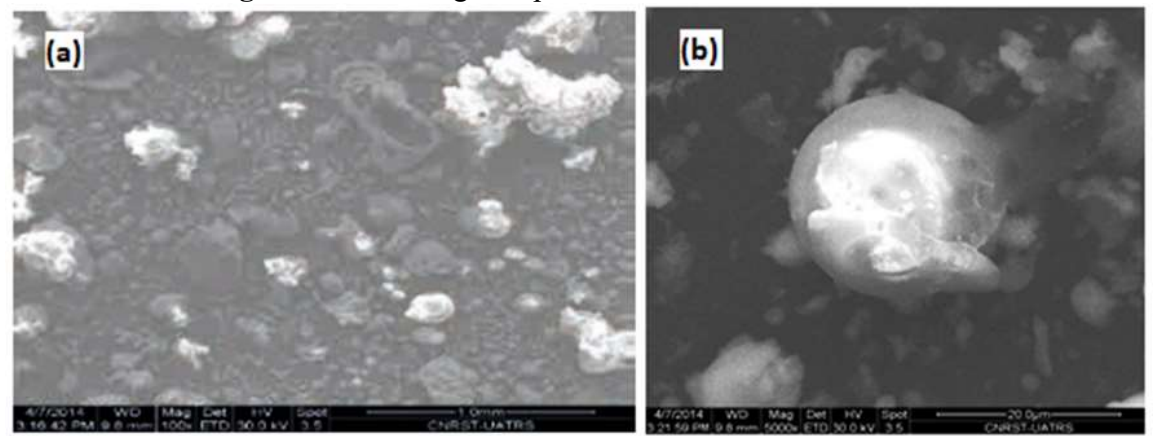

Fig.7 SEM images of Bottom ash morphology: (a) $1.0 \mathrm{~mm}$ level and (b) $20.0 \mu \mathrm{m}$.

Figure 7 shows the morphological structure of the crude ash obtained before filtration: they are in the form of spherical particles with irregular sizes that revealed the presence of porosity [21]. Most grains of cement are in the form of hollow spheres or spheres filled with smaller spheres. Micro crystals are also present on the surface of the particles, which reveal the presence of Mullite and Quartz. The elements $\mathrm{Si}, \mathrm{Al}, \mathrm{Ca}, \mathrm{Na}$ and small amounts of Fe are contained in the plot spheres. 


\section{Experiment and materials description}

\subsection{Magnetization of water}

The natural water was treated by an electromagnetic source of $40 \mathrm{nT}$, using a generator machine (Figure 8).

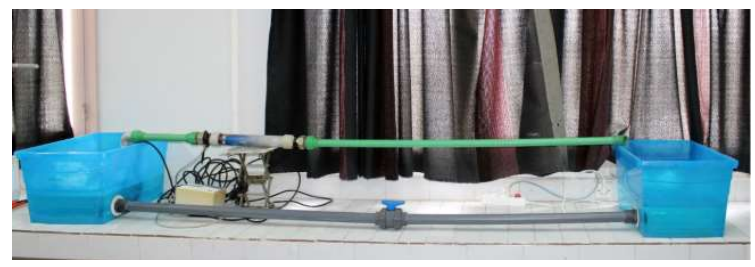

Fig. 8 Magnetic water production machine

The water flow can be adjusted by a differential regulator (PID) (Figure 8). When water crosses this electromagnetic field, it becomes magnetized.

\subsection{Measurement of the mechanical properties}

The test of the mechanical resistance to bending of mortars was realized on a material characterization machine (figure 9). The experimental protocol used is described by standard EN 196-1.
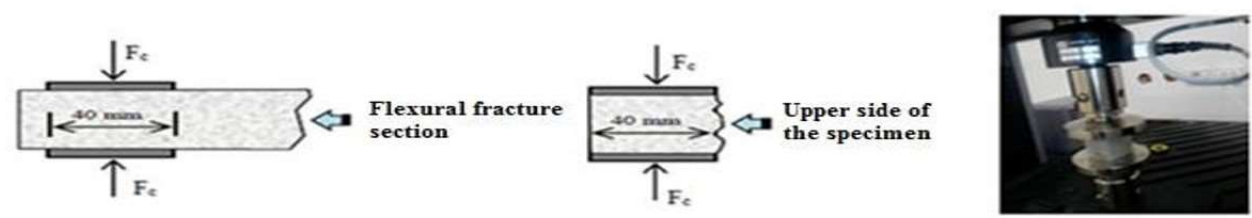

Fig. 9 Mechanical bending strength test instrument 
The expression of resistance to the load applied to the center of the prism is expressed as

$$
\text { follows, } \mathrm{R}_{\mathrm{f}}=3 F_{f} L / 2 b^{3}
$$

$F_{f}$ load applied to the center of the prism at break (N)

$L:$ distance between supports $(\mathrm{mm})$

$b$ :side of the square section of the prism ( $\mathrm{mm})$

After bending, each half-prism was reused to test the compressive strength (Figure 6)[8].
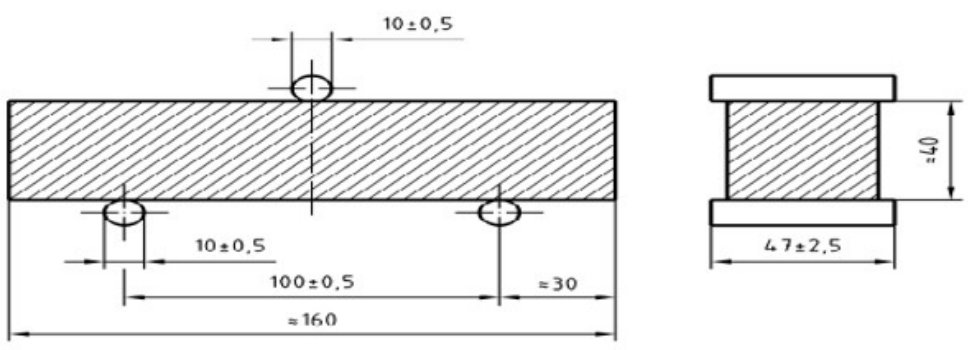

Fig. 10 Device for testing mechanical properties

A progressive force was on the cross-section $(4 \times 4 \mathrm{~cm})$ of the test piece with the same speed up to the breaking load from which the mechanical resistance to compression can be obtained in mega-pascals as follows.

$$
\mathrm{R}_{\mathrm{c}}=F_{c} / b^{2}
$$

Fc: Maximum load at break (N)

$b$ : side of the square section of the prism $(\mathrm{mm})$

The authors produced a cement-based mortar with $10 \%$ fly ash and a water/cement ratio (W/CM) equal to 0.5 .

\section{Results and discussion}

\subsection{Physico-chemical parameters of tap and magnetized water}

The different Physico-chemical parameters of natural water and magnetized water we represented in table 7 , in order to observe the impact of the magnetic field on the water properties. Thus, the application of a magnetic field on water increases the value of $\mathrm{pH}$ from 7.69 to 8.25 [22] and decreases its conductivity from $1695 \mu \mathrm{S} / \mathrm{Cm}$ to $971 \mu \mathrm{S} / \mathrm{Cm}$. The value of TDS is also decreasing dramatically from 848 to $485 \mathrm{mg} / \mathrm{l}$. For other parameters associated with the concentration of $\mathrm{Ca}, \mathrm{Cl}$ and $\mathrm{TH}$ they stay the same. 
Table7 Physico-chemical analysis of natural water and magnetized water

\begin{tabular}{lcc}
\hline Parameters & Tap water & Magnetized water \\
\hline pH & 7.69 & 8.25 \\
Conductivity $(\boldsymbol{\mu S} / \mathbf{C m})$ & 1695 & 971 \\
TDS(mg/L) & 848 & 485 \\
Ca(mg/L) & 78.5 & 79 \\
Oxydability $(\mathbf{m g} / \mathbf{L})$ & 0.41 & 0.49 \\
Chloride(mg/L) & 88.5 & 89 \\
Temperature $\left({ }^{\circ} \mathbf{C}\right)$ & 17.8 & 17.8 \\
Mg(mg/L) & 23.83 & 23.9 \\
Alkalinity $\left({ }^{\circ} \mathbf{F}\right)$ & 10.35 & 10.4 \\
TH or title hydrometric(meq/l) & 2.94 & 2.98 \\
Ammonium(mg/L) & 0.00 & 0.00 \\
Fer(mg/L) & 0.00 & 0.00 \\
\hline
\end{tabular}

\subsection{Results of mechanical tests on mortars 4.2.1 Flexural strength test (FS)}

Figures 11 and 12, presents the variations in the average flexural strength (FS) mortars produced from fly ash and bottom ash, in place of cement, with a water/cement ratio equal to 0.5 at different times of water magnetization, $0 \mathrm{~min}, 10 \mathrm{~min}, 20 \mathrm{~min}, 30 \mathrm{~min}$, and $40 \mathrm{~min}$. We have observed that for all mortars containing magnetized water, a higher flexural resistance than those developed with natural water which doesn't exceed the value of $3.80 \mathrm{MPa}$ for the FS of mortar based on $10 \%$ bottom ash and $3.44 \mathrm{MPa}$ for the FS of mortar based on $10 \%$ fly ash. In summary, the extension of time of magnetization increases the FS of the mortar. The optimal time of magnetization of water is $30 \mathrm{~min}$ which increases the value of FS to $4.5 \mathrm{MPa}$ for a mortar based on $10 \%$ bottom ash or $10 \%$ of fly ash, after $30 \mathrm{~min}$ as a time of magnetization, the value of FS remains almost constant, which indicates the saturation phenomenon to magnetization. 


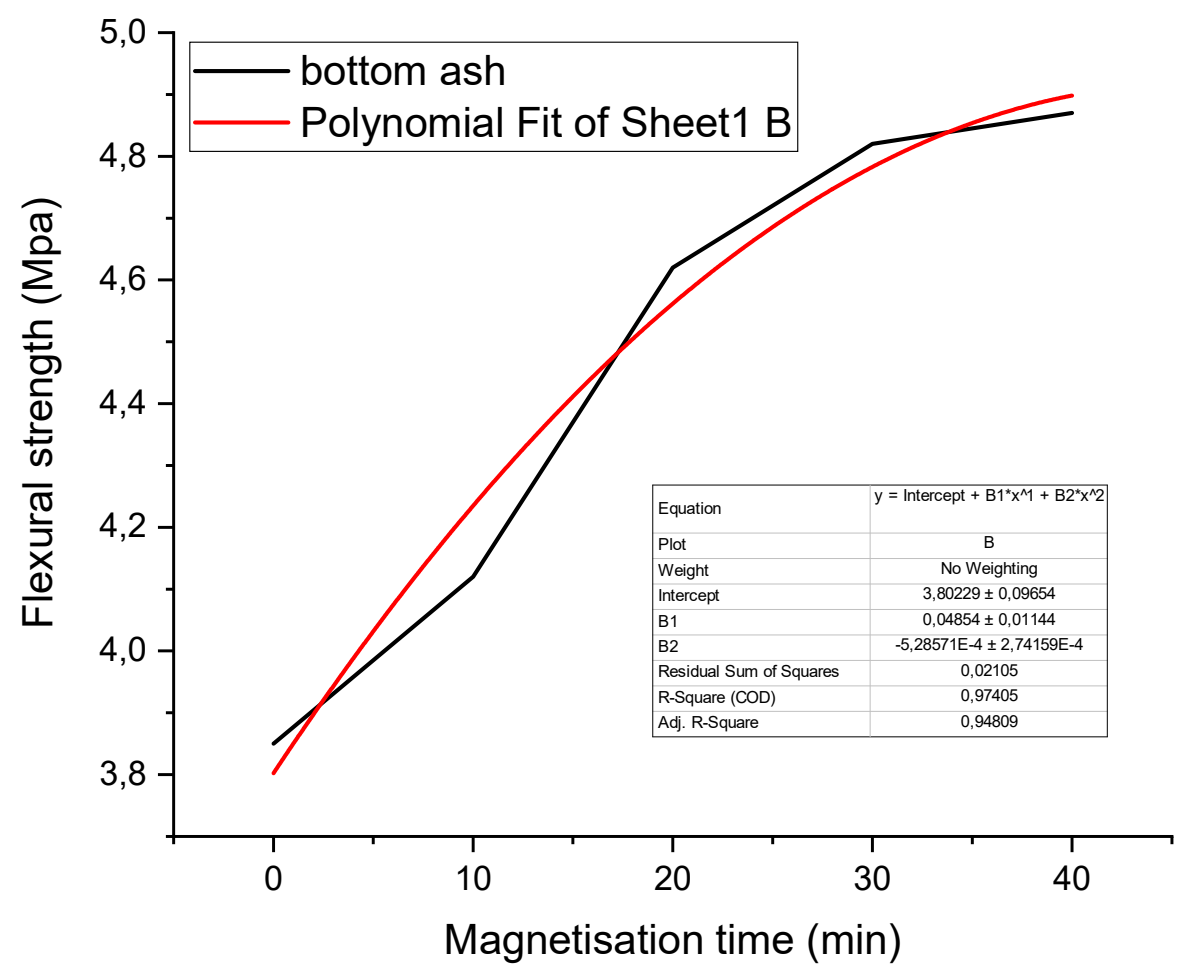

Fig. 11 Effect of EMF on the flexural strength of mortar based on $10 \%$ bottom ash

Table 8 ANOVA analysis of Flexural strength of bottom ash

\begin{tabular}{lllllll}
\hline & & DF & Sum of Square & Mean Square & F Value & Prob $>$ F \\
\hline $\begin{array}{l}\text { Flexural } \\
\text { strength }\end{array}$ & Model & 2 & 0,78987 & 0,39494 & 37,53136 & 0,02595 \\
\hline $\begin{array}{l}\text { Flexural } \\
\text { strength }\end{array}$ & Error & 2 & 0,02105 & 0,01052 & & \\
\hline $\begin{array}{l}\text { Flexural } \\
\text { strength }\end{array}$ & Total & 4 & 0,81092 & & & \\
\hline
\end{tabular}

From figure 11 we see that the most important result is to record with an $\mathrm{R}^{2}(0.94)$. In this study, ANOVA analysis and $\mathrm{F}$ tests were performed to determine the statistically significant process parameters. If the critical $\mathrm{F}$ value is less than the calculated $\mathrm{F}$ value, there is a direct relationship between independent and dependent variables. The critical F-value is less than the calculated F-value $(37,53136)$. As the P-value $(0,02595)$ is much lower than 0.05 , which proves the great significance of Flexural strength of bottom ash testing (table 8).

The figure 11 show the equation of the Flexural strength of bottom ash as a function of the magnetization time 


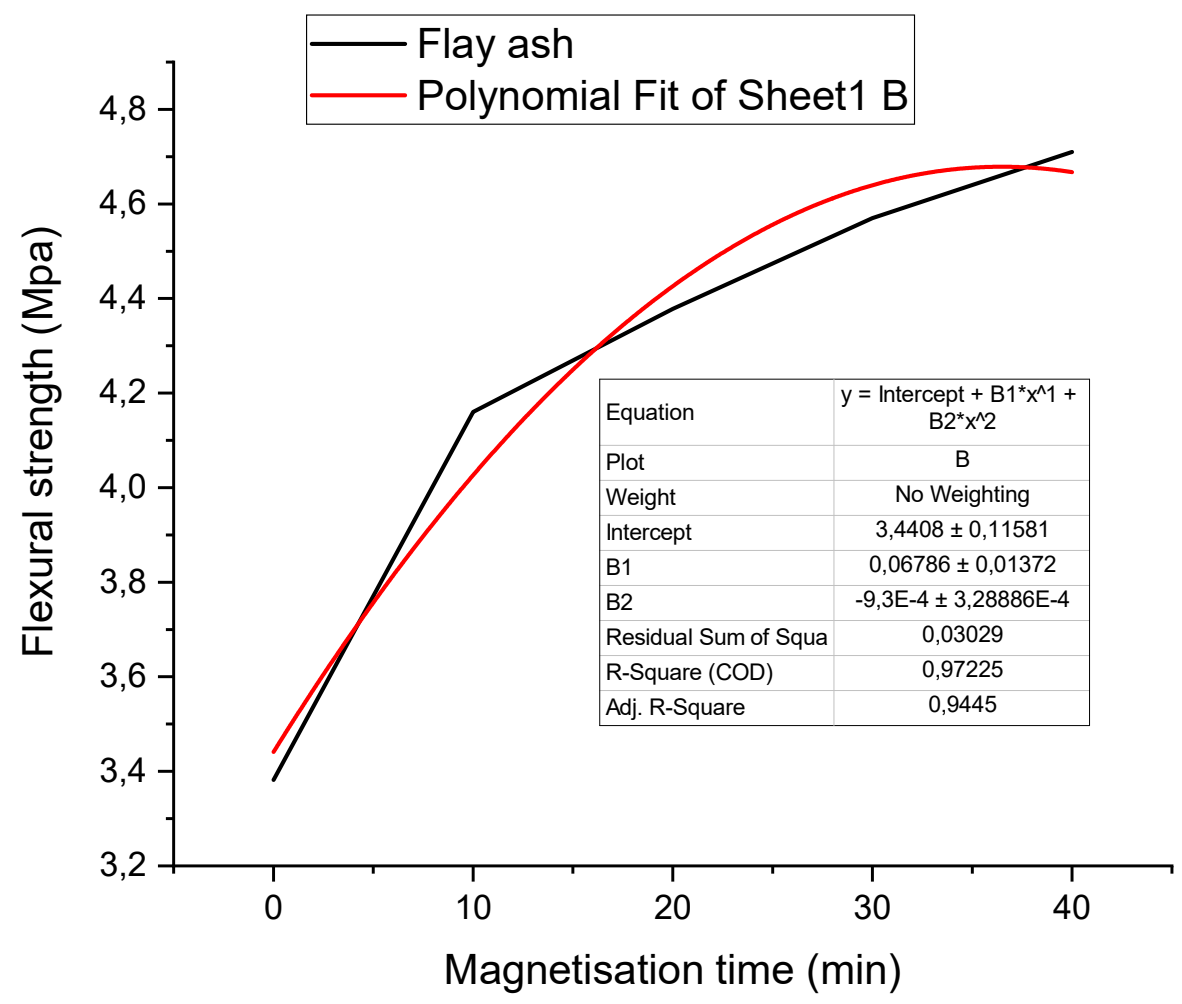

Fig. 12 Effect of EMF on the flexural strength of mortar based on $10 \%$ fly ash

Table 9. ANOVA analysis of Flexural strength of fly ash

$\begin{array}{lccccr} & \text { DF } & \text { Sum of Square } & \text { Mean Square } & \text { F Value } & \text { Prob }>\text { F } \\ \text { Flexural strength Model } & 2 & 1,06112 & 0,5305 & 65,03624 & 0,02775 \\ \text { Flexural strength Error } & 2 & 0,03029 & 0,01514 & & \\ \text { Flexural strength Total } & & 41,09141 & & & \end{array}$

From figure 12 we see that the most important result is to record with an $\mathrm{R}^{2}(0.94)$. In this study, ANOVA analysis and $\mathrm{F}$ tests were performed to determine the statistically significant process parameters. If the critical $\mathrm{F}$ value is less than the calculated $\mathrm{F}$ value, there is a direct relationship between independent and dependent variables. The critical F-value is less than the calculated F-value $(65,03624)$. As the P-value $(0,02775)$ is much lower than 0.05 , which proves the great significance of Resistance to compression of bottom ash testing (table 9). The table in figure 12 show the equation of the Flexural strength of fly ash as a function of the magnetization time. 


\subsubsection{Compressive strength test}

Figure 13 and 14 presents the variations in the average compressive force Mortars based on fly as hand bottom ash used in place of cement. With a water/cement ratio equal to 0.5 at different times of water magnetization, $0 \mathrm{~min}, 10 \mathrm{~min}, 20 \mathrm{~min}, 30 \mathrm{~min}$, and $40 \mathrm{~min}$, we note for all mortars containing magnetized water, higher compressive strength than those developed with tap water. For tap water, the value of compressive strength Mortar based on bottom ash is $7.5 \mathrm{MPa}$ and $13.8 \mathrm{MPa}$ for fly ash. In presence of magnetic water, we observe an increase of resistance to compressive strength. The optimum time of magnetization is equal to $30 \mathrm{~min}$, after this value, the resistance to the compressive strenght remains constant (saturation to magnetization).

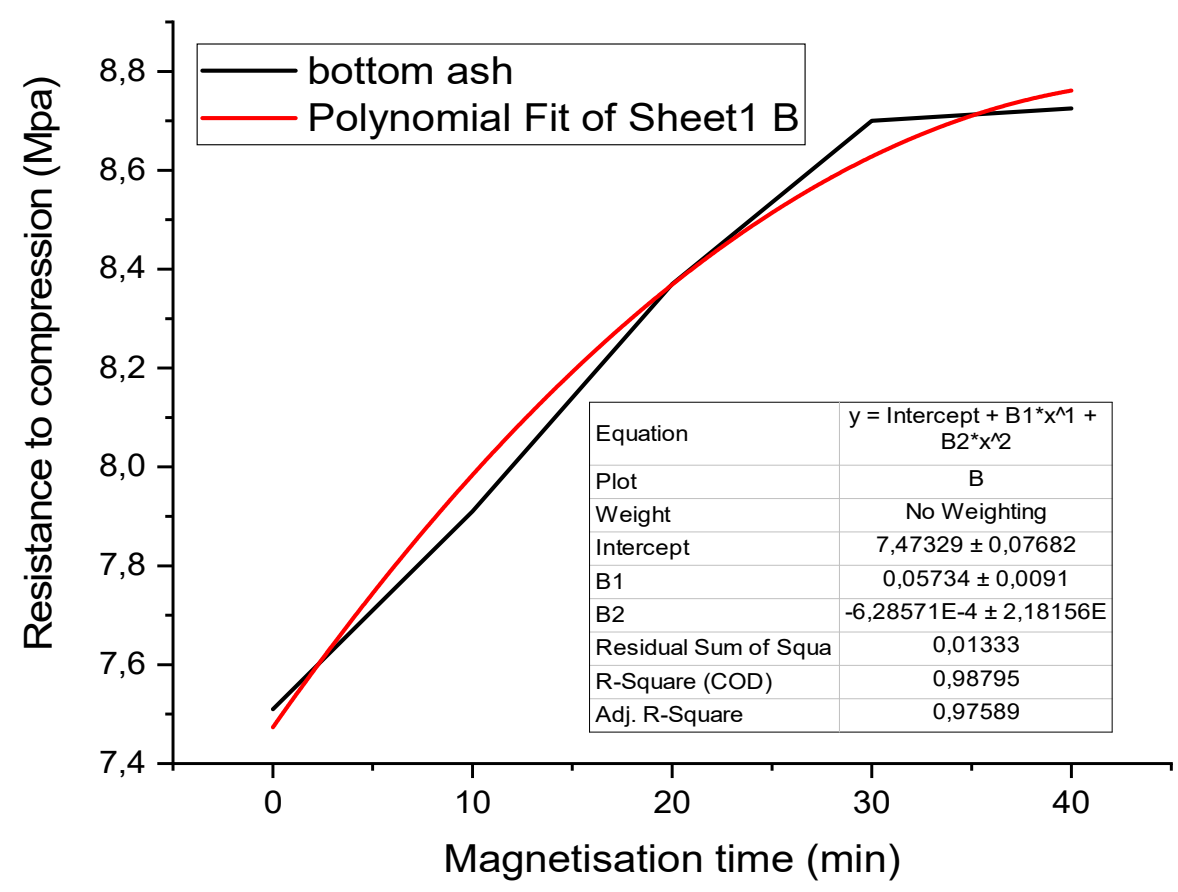


Fig. 13 Effect of EMF on the Resistance to compression of mortar based on 10\% bottom ash

Table10. ANOVA analysis of Resistance to compression of bottom ash

\begin{tabular}{|c|c|c|c|c|c|}
\hline & & DF Sum of Squares & MeanSquare & FValue & Prob $>F$ \\
\hline Resistance to compression & Model & 1,09215 & 0,54608 & 81,9584 & 0,01205 \\
\hline Resistance to compression & Error & 20,01333 & 0,00666 & & \\
\hline Resistance to compression & Total & 1,10548 & & & \\
\hline
\end{tabular}

From figure 13 we see that the most important result is to record with an $\mathrm{R}^{2}(0.98)$. In this study, ANOVA analysis and $\mathrm{F}$ tests were performed to determine the statistically significant process parameters. If the critical $\mathrm{F}$ value is less than the calculated $\mathrm{F}$ value, there is a direct relationship between independent and dependent variables. The critical F-value is less than the calculated F-value $(81,9584)$. As the P-value $(0,01205)$ is much lower than 0.05 , which proves the great significance of Resistance to compression of bottom ash testing (table 10). The table in figure 13 show the equation of the Resistance to compression of bottom ash as a function of the magnetization time.

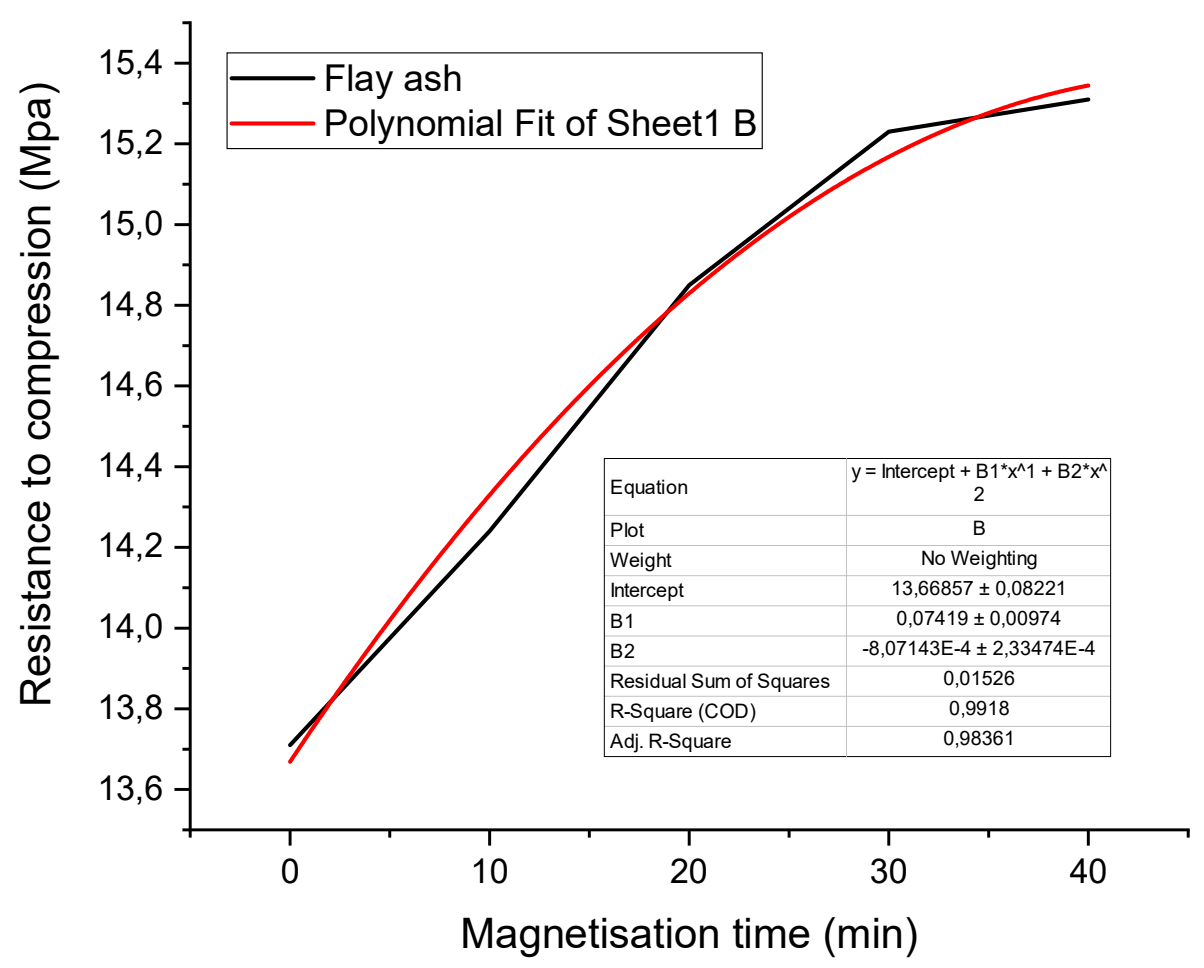

Fig. 14 Effect of EMF on the Resistance to compression of mortar based on10 \% fly ash 
Table 11 ANOVA analysis of Resistance to compression of fly ash

\begin{tabular}{llcrcrr} 
& & DF & \multicolumn{2}{c}{ Sum of Square Mean Squar } & F Value & Prob $>$ F \\
Resistance to compression & Model & 2 & 1,84682 & 0,92341 & 121,00075 & 0,0082 \\
Resistance to compression & Error & 2 & 0,01526 & 0,00763 & & \\
Resistance to compression & Total & 4 & 1,86208 & & &
\end{tabular}

From figure 14 we see that the most important result is to record with an $\mathrm{R}^{2}(0.98)$. In this study, ANOVA analysis and $\mathrm{F}$ tests were performed to determine the statistically significant process parameters. If the critical $\mathrm{F}$ value is less than the calculated $\mathrm{F}$ value, there is a direct relationship between independent and dependent variables. The critical F-value is less than the calculated F-value $(121,00075)$. As the P-value $(0,0082)$ is much lower than 0.05 , which proves the great significance of Resistance to compression of fly ash testing (table 11). The table in figure 14 show the equation of the Resistance to compression of fly ash as a function of the magnetization time.

\subsubsection{Interpretation of Flexural strength test and Compressive strength test}

The interpretation of the previous results of flexural force and compressive force tests can be explained by the fact that the electromagnetic field change the structure of water molecules clusters (break of the macro clusters water molecules into small clusters of water, So they can easily penetrate the central part of the cement grains, increasing its resistance compared to mortar realized by natural water which forms larger clusters). Thus, with natural water we obtain incomplete hydration leading to bad mechanical properties [21,23]. Furthermore, the magnetized water can act as a dispersing agent, which improves the fluidity of the mortar increasing its quality in construction.

\section{Conclusion}

The magnetic field on water increases the value of $\mathrm{pH}$ and decreases its conductivity and its TDS. The concentration values of elements as $\mathrm{Ca}, \mathrm{Cl}$, and $\mathrm{TH}$ remain fixed after magnetization of water. For all mortars produced with magnetized water, we observed a higher flexural resistance than those with natural. The optimal time of magnetization of water is $30 \mathrm{~min}$ after this time of magnetization, the values of flexural and compression resistance remain constant, which indicates the phenomenon of saturation to magnetization. The electromagnetic field generated an electromagnetic force which can break the macro clusters water molecules into small clusters, thus they can easily penetrate the central part of the cement grains, increasing the resistance of mortar.

\section{References}

[1] N. Mahasenan, S. Smith, K. Humphreys, In Greenhouse Gas Control Technologies - 6th International Conference; Gale, J., Kaya, Y., Eds.; Pergamon: Oxford, 2,995(2003)

[2] P.Ubale, D. R. Pandit, P .A. Wadekar, Int. j. sci. technol. manag.,5,68(2016)

[3] M. C. Amiri, A. A. Dadkhah. Colloids Surf. A: Physicochem. Eng. Asp., 278,252 (2006)

[4] J. S. Baker, S. J. Judd. Water Res., 30, 247 (1996)

[5] A. Bubnov, V. Novotná, V. Hamplová, M.Kašpar, M. Glogarová, J. Mol. Structure, 892, 151 (2008)

[6] R. Cai, H. Yang, J. He, W. Zhu, J. Mol. Structure, 938, 15 (2009)

[7] A. C. Cefalas, E. Sarantopoulou, Z. Kollia, C. Riziotis, G. Dražic, S. Kobe, et al. J. Comput. Theor. Nanosci., 7, 1800 (2010)

[8] K. T. Chang, C. I. Weng, J. Appl. Phys., 100, 1 (2006) 
[9] M. C. Chang, C. Y. Tai, Chem. Eng. J. 164, 1 (2010)

[10] E. Chibowski, L. Hołysz, A. Szcześ, Water Res., 37, 4685 (2003)

[11] E. Chibowski, A. Szcześ, Chemosphere, 203, 5 (2018)

[12] K. X. Zhou, G. W. Lu, Q. C. Zhou, J. H. Song, S.T. Jiang, H. R. Xia..J. Appl. Phys., 88, 1802 (2000)

[13] X. F. Pang, B. Deng, B. Tang, Mod. Phys. Lett. B, 26, 1 (2012)

[14] H. Wei, Y. Wang, J. Luo.Constr. Build. Mater,147,91(2017)

[15] R. Mghaiouini et al., Indian. J. Sci. Technol.,13, 1172, (2020)

[16] R. Mghaiouini et al., J. Ecol. Eng., 21, 245 (2020)

[17] R. Mghaiouini, M. Salah, M. Monkade, A. El Bouari, Arab. J. Sci. Eng. (2021)

[18] S. Ghorbani, M. Gholizadeh, J. D. B. Pavers, Mater., 11, 1 (2018)

[19] A. R. Esfahani, M. Reisi, B. Mohr, J. Mater. Civ. Eng.,30,1(2018)

[20] M. Gholhaki, A. kheyroddin, M. Hajforoush, M. Kazemi, Constr. Build. Mater.,158, 173 (2018)

[21]N. Su, C. F. Wu, Cem. Concr. Compos., 25, 681 (2003)

[22] R. Mghaiouini, A. Elmlouky, M. Salah, T. M. Al Antary, M. Monkade, A. El Bouari, A. Y. Ghidan Fresenius Environ. Bull. 29, 7922(2020)

[23] T. IM. Abdel-Magid, R. M. Hamdan, A. AB. Abdelgader, M. EA. Omer, N. M. R. Ahmed, Proc. Eng., 193, 494 (2017) 